\title{
Las enseñanzas de una sociedad agraria tradicional: bienes de uso cotidiano y patrimonio mueble en los Pedroches (Córdoba)
}

\begin{abstract}
La cultura material de la sociedad agraria de los Pedroches es un patrimonio escasamente conocido pero, al igual que otros, ha contribuido a crear la identidad propia y específica de la comarca. La consideración del significado de las cosas de uso cotidiano, y que normalmente se vienen catalogando como objetos etnográficos, es el objetivo de este trabajo. La cultura material de los Pedroches constituye una expresión excepcional más del acervo de una sociedad, que no solo ha configurado unos paisajes humanos y agrarios diferenciados en sintonía con el medio físico donde se inserta, sino que también ha sabido resolver las necesidades de la vida cotidiana de forma sostenible.
\end{abstract}

Ricardo Manuel Luque Revuelto | Universidad de Córdoba

URL del acontribución <www.iaph.es/revistaph/index.php/revistaph/article/view/3898>

\section{Introducción}

Las enseñanzas que se pueden extraer de la cultura material de los Pedroches apuntan en el mismo sentido que el estudio de otras dimensiones culturales y patrimoniales de la comarca. Su extraordinario patrimonio ya ha sido puesto de relieve en numerosos estudios que enfatizan la existencia de unos componentes geológicos y litológicos propios (CABANAS, 1967), de unos paisajes naturales emblemáticos (TORRES ESQUIVIAS, 1994), de unos aprovechamientos agrarios sostenibles (VALLE BUENESTADO, 1986), de un hábitat rural característico (LUQUE REVUELTO, 2012a) y de otros aspectos que incluyen tanto componentes inmateriales como materiales de la cultura de esta comarca de Sierra Morena. Entre los primeros destacan, las tradiciones, la gastronomía o su folklore (AGUDO TORRICO, 2014); entre los segundos sus bienes arqueológicos, monumentos y la existencia de piezas etnográficas, resultado de unas técnicas artesanales tradicionales.

La comarca de los Pedroches y sus 17 municipios se extiende sobre una superficie de $3.612 \mathrm{~km}^{2}$ y forma parte de la Sierra Morena Cordobesa, que igualmente es depositaria de un importantísimo patrimonio, el cual es expresión y vínculo de las relaciones entre la población y el territorio (FERNÁNDEZ CACHO; FERNÁNDEZ SALINAS; HERNÁNDEZ LEÓN et ál., 2010; VALLE BUENESTADO, 2016). Así este patrimonio, expresión máxima de su acusada personalidad geográfica, es el resultado de una historia de siglos en la que la comarca quedaba emplazada en una situación de frontera a lo largo de diferentes etapas históricas y en una posición periférica respecto a los centros urbanos y de poder hasta el presente. Sin embargo, en su evolución reciente no solo se ha producido una regeneración medioambiental -gracias a la débil presión humana y a sus potencialidades- y agraria -consecuencia de las ayudas comunitarias al desarrollo de la ganadería y el olivar en las zonas de montaña-, sino también una renovada conciencia acerca del valor de su cultura material. Como consecuencia han ido apareciendo en diferentes localidades centros de interpretación y distintos museos que recogen las expresiones culturales y materiales del devenir de la comarca, con especial énfasis en las prácticas y técnicas agrarias tradicionales.

Dichos espacios son contenedores de una multitud de objetos que son testimonio de un pasado reciente relacionado con la vida cotidiana de los pueblos y de las faenas agrícolas del campo. Muchos de los objetos expuestos son reconocidos por los visitantes de la comarca como utensilios de uso cotidiano, empleados por ellos mismos en su juventud -en el caso de las personas ya mayores- o por sus ascendientes. Estos objetos se encuentran expuestos con intención museística porque sirven para explicar los procesos sociales, económicos y culturales de la comarca, aunque muchos de ellos se custodian también por las cualidades materiales 


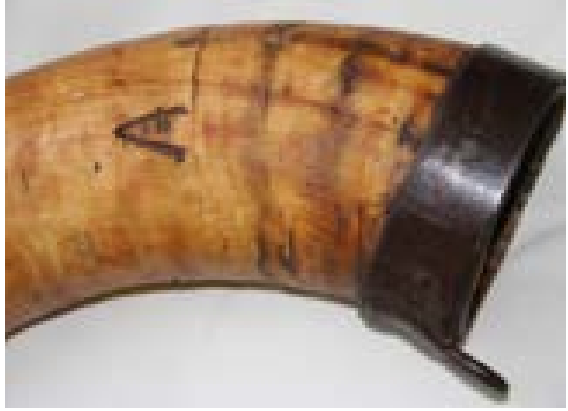

Cuerno de vaca con la inicial del propietario. Utilizado por los pastores como envase de alimentos

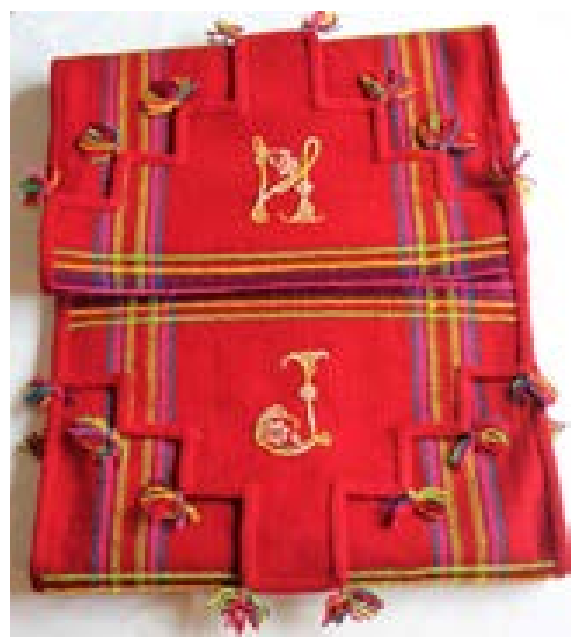

Alforjas de paño de excepcional calidad (fábrica de los Muñoces de Pozoblanco) con bordado de canutillo. Segunda mitad del siglo XIX

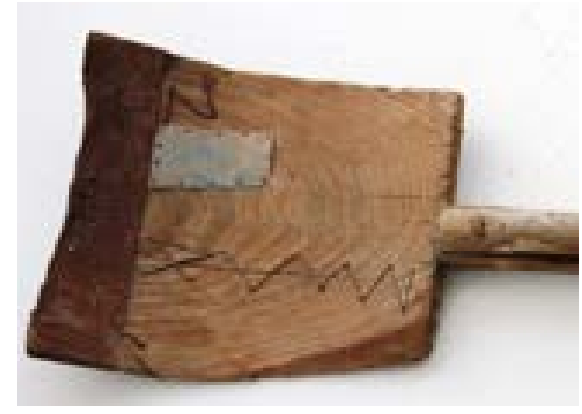

Pala de aventar con múltiples reparaciones

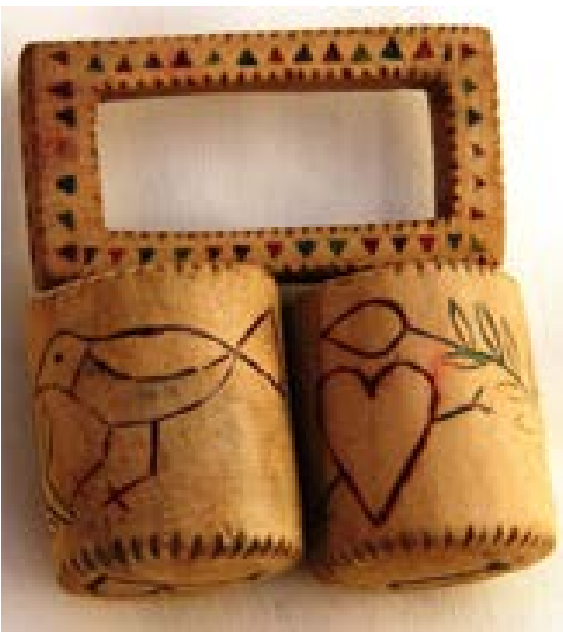

Sello de pan. Madera, decoración incisa y polícroma. Se trataba de objeto de uso cotidiano y a la vez dote de matrimonio

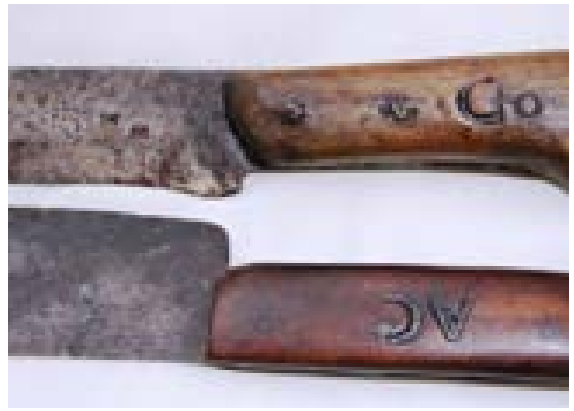

Cuchillos matanceros de acero y madera con las iniciales de su propietario talladas

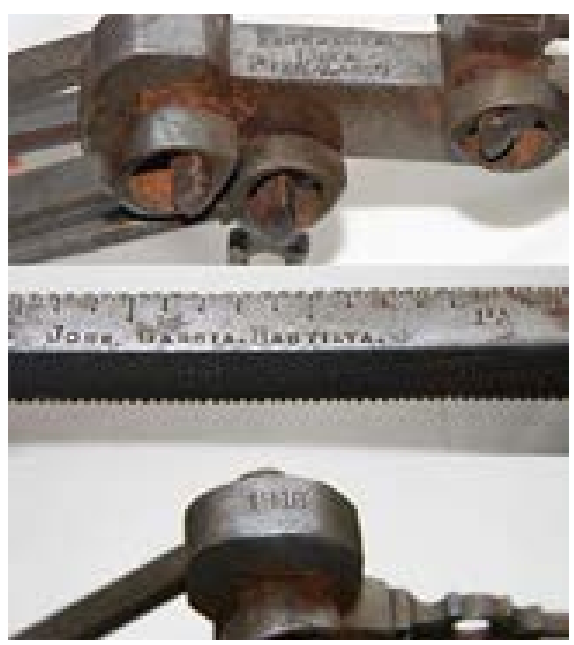

Romana de forja de tres ganchos realizada por encargo. Cincelados el nombre del propietario, el del artesano y la fecha de fabricación o estéticas que presentan, y que en algunas piezas los hacen excepcionales. El patrimonio etnográfico, como cualquier otro patrimonio, genera una identidad específica y propia en la que se reconocen sus habitantes y, además, una valoración de los saberes tradicionales, de los oficios artesanos y de las labores de las mujeres, que en posesión de un saber hacer ancestral, han perpetuado un patrimonio vivo e identitario.

Han sido las iniciativas de los municipios y sus habitantes los que han promovido el rescate de todo aquello que se considera el vestigio de la cultura tradicional, con el mismo sentido y forma que la antropología o la etnografía. Es decir, coleccionando, clasificando, estudiando y exponiendo los objetos en unos recintos cerrados con mayor o menor acierto, disponibilidades presupuestarias y no pocas dificultades.

Ahora bien, la cultura material de la sociedad agraria de los Pedroches, que vienen recogiendo los museos, no puede caer en la misma dinámica que los vestigios de otras culturas anteriores, que permanecen expuestos, perdido su nexo de unión con el presente, objetos arqueológicos sometidos a estudio científico y que despierten solo un interés académico.

Por el contrario, los bienes de uso rescatados debieran de ser nuevamente conceptualizados como "bue- 


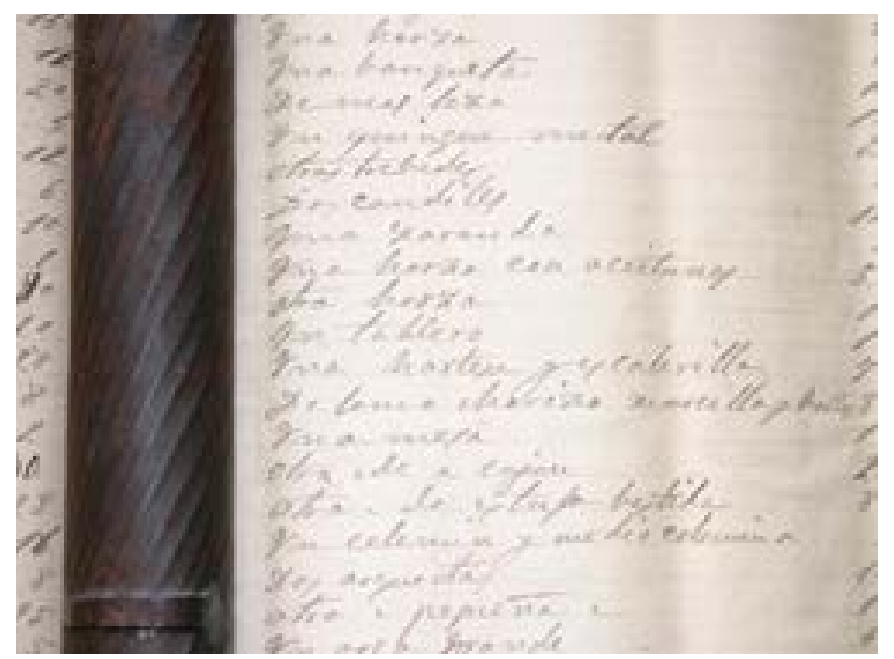

Carta dotal junto al cilindro metálico donde se guardaba, fechada en 1926. Es un documento, muy frecuente en la época, que enumera los bienes de uso cotidiano que se aportaban al matrimonio. Es reflejo del valor de las cosas de uso cotidiano en esta sociedad agraria

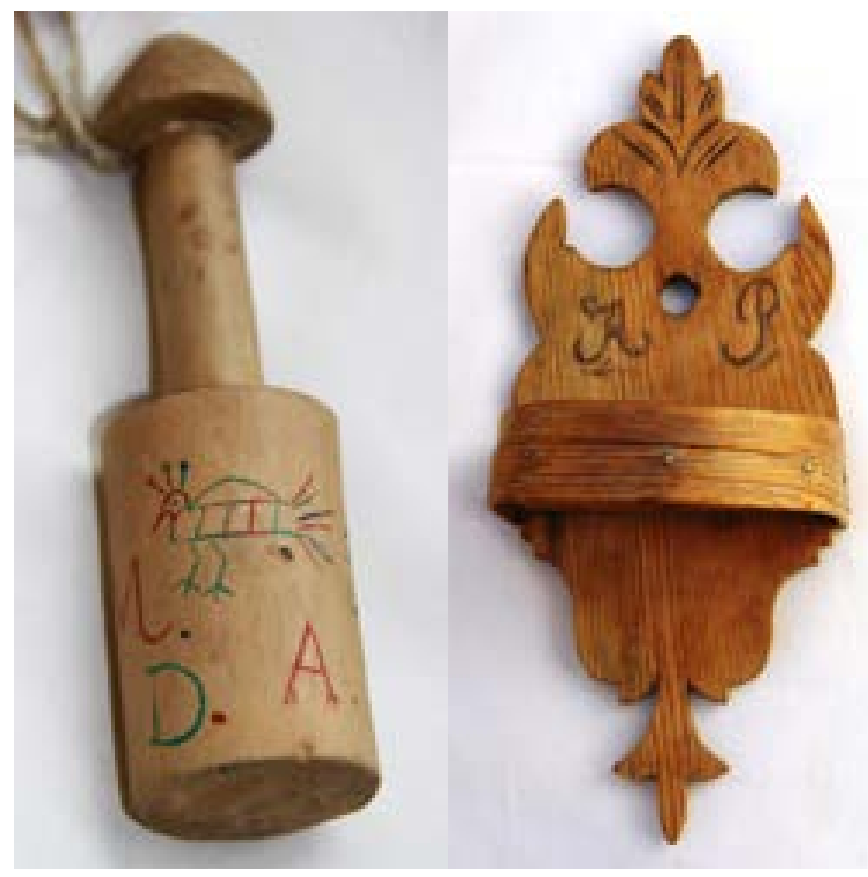

Izquierda. Detalle de un bolillo. Madera, decoración incisa y policroma. Empleado para hacer las labores de encaje

Derecha. Vasero realizado en madera de pino pinaster con las iniciales de sus propietarios. Se colgaba junto al cabecero de las camas para colocar un vaso de agua | fotos Ricardo M. Luque, autor de toda las imágenes. Las piezas pertenecen a una colección privada nos para pensar", según las palabras de Lévi-Strauss, y considerados como una cultura material que muestra no solo sus atributos -técnicos, materiales, etc.- sino también los contextos que le dan sentido y significado.

En un sentido antropológico son medida y expresión de las relaciones sociales de una sociedad agraria; en sentido histórico son la herencia y la manifestación de las formas de vida de los habitantes de la comarca; vistos desde la geografía expresan la relación y el entendimiento entre el medio físico, sus recursos, los diferentes aprovechamientos agrarios y las formas de vida de sus habitantes; desde la didáctica o enseñanza de las ciencias sociales constituyen un objeto de estudio significativo que permite una aproximación conceptual -a los hechos geográficos, históricos o patrimoniales-, el desarrollo de destrezas y el fomento de actitudes favorables a su valoración y conservación. Incluso vistos desde el punto de vista del lenguaje se podría afirmar que dichos objetos se cifran con su propia gramática y vocabulario.

Por tanto, se puede acceder al estudio de esta cultura material desde distintos puntos de vista, siendo todos ellos complementarios y necesarios, pero sin perder de vista el contexto social en el que realmente cobran significado (MALINOWSKI, 1931; APPADURAI, 1991). En este sentido interesa apuntar una serie de claves interpretativas cuando nos acerquemos a su estudio detallado:

Los artefactos de uso cotidiano, como expresa la ontología de Bunge, poseen propiedades sustanciales pero adquieren, en un contexto que les da sentido, determinadas propiedades conceptuales, pudiendo asimismo devenir en constructos. Los pastores, jornaleros, piconeros, materos, labradores, colmeneros, pareeros, etc. con sus atuendos, herramientas y escasas pertenencias vivían y, a su vez, modelaban unos paisajes forestales, de dehesa o de olivar que a su vez permitían su sustento y el de sus familias. Así, el saber hacer y conservar unos aperos de labranza, un dornajo o unas cucharas de madera, unas liaras, un zurrón, la ropa que vestían, etc. convertía dichos objetos en portadores de un valor intrínseco, pero también de un valor social, y aún en instancias de afectividad.Todo ello sin perder de 
vista los atributos físicos y estéticos que los caracterizan materialmente.

\section{Atributos físicos}

La misma selección de los materiales empleados (madera, fibras vegetales, hueso, pieles, metales, piedra, etc.) en la confección de los objetos de uso cotidiano muestra la intrínseca relación que existe entre estos y el medio, de manera que todos aquellos que se acercan a su estudio o a su contemplación pueden apreciarla.

La uniformidad de las técnicas empleadas, la escasa variedad de tipos y sus dimensiones contenidas, son otros atributos que los caracterizan y que, en definitiva, muestra una realidad material que se fundamenta en el acervo común de una sociedad agraria por explotar y convivir en un medio frágil en el cual tiene el campesino que construir unos utensilios que le permitan efectuar los necesarios aprovechamientos agrícolas.Asimismo esta cultura material, entronca con unas austeras formas de vida y un hábitat rural de gran modestia constructiva (LUQUE REVUELTO, 2012b). Es así como en todos los objetos, aunque las formas o la funcionalidad sea diferente, predomina un sentido unitario y simbiótico con el medio de donde proceden, sentido que adquieren por la utilización de unos materiales y unas técnicas tradicionales.

Con todo, dicho sentido unitario no está reñido con una cierta diversidad de tipologías y formas, dado que los artefactos cotidianos son obra de la iniciativa de artesanos locales o de los mismos campesinos que en la medida de sus posibilidades, la disponibilidad de materias primas o de las necesidades del momento elaboran lo que precisan para su existencia material. La austeridad o modestia de los objetos elaborados se muestra por su escasa entidad y la práctica ausencia de elementos decorativos, en los que predomina un sentido práctico, en consonancia con una sociedad que obtiene escasos rendimientos de la tierra que explota y que por tanto solo nos permite descubrir en las salas de los museos etnográficos lo que fuera estrictamente necesario para el agricultor y su familia. Sin embargo esta modestia no está reñida con una gran calidad formal y estética de los objetos, fruto de una profunda sensibilidad tradicional.
La anterior característica tampoco está reñida con apreciable resistencia y durabilidad de los objetos de uso cotidiano. La razón de ello estriba en el empleo de unas técnicas acrisoladas a lo largo de generaciones y de unos materiales sólidos como, por ejemplo, la madera de encina. Estas particularidades físicas de la cultura material de los Pedroches han contribuido a que se establezcan claras diferencias con el resto de la provincia de Córdoba, presentando en cambio más analogías con la penillanura extremeña, en razón de las similitudes del medio físico y los aprovechamientos agrarios predominantes.

\section{El valor}

Los bienes muebles guardan diferentes valores: el de uso por quienes los emplearon, el valor intrínseco o económico pasado o presente, y el que actualmente se les da desde el punto de vista del patrimonio. Cuando se analiza el cambio de valor de los objetos resulta útil remitirse al concepto de biografía de los objetos y vida social de los mismos (APPADURAI, 1991). En este sentido conviene insistir en el valor que la sociedad agraria tradicional otorgaba a los mismos. En los archivos de protocolos notariales de la comarca se localizan testamentos, dotales matrimoniales o particiones en las que se hacen relaciones materiales de los bienes muebles de las personas. En estos inventarios se detallan con precisión hasta los objetos más modestos, desde un hocino hasta un bieldo o un pañuelo, es decir todos los objetos que poseían, desde el más humilde campesino hasta el mediano o gran propietario. De ello se encargaba una figura muy conocida en los pueblos, denominada apreciadora, que valoraba herencias o ajuares domésticos en unos pliegos que no siempre pasaban por las notarías, pero que guardados en un cilindro metálico, eran válidos para reclamar las dotes en caso de que no hubiese descendencia (MORENO VALERO, 2001).

Por tanto, en la documentación histórica se encuentra la relación de bienes y el valor económico que los objetos poseían en el momento de su uso. El análisis de dichas relaciones conduce a la consideración de que además los objetos de uso cotidiano se transmitían de padres/ madres a hijos/hijas, y cuando el uso continuado los deterioraba eran reparados: zurcidos los tejidos, restau- 
rados los objetos de cerámica o madera por el lañero, los metálicos por el latonero, etc. Incluso si el objeto ya no era útil se transformaba para darle un nuevo uso, por ejemplo: un sello de pan podía ser trasformado en mazo de madera para el latonero o un zuncho de lobos se transforma en un gancho para el ganado, etc.

Otra muestra del valor que se concedía a los objetos es que se señalaban con el nombre o las iniciales de su propietario, en el caso de los tejidos se bordaba, en los objetos de madera se tallaba en lugar bien visible, en los metálicos se cincelaba con buriles o incluso, en el caso de objetos valiosos como las romanas, aparecía el nombre completo.

\section{Afectividad}

La cultura material no está constituida tan solo por los objetos que las personas elaboran, usan y heredan. Es una parte integral de la experiencia humana y en ella interviene también la tradición y los contextos rituales. Cuando los objetos son embellecidos estéticamente estos adquieren una nueva dimensión, en donde unos nuevos valores sociales, sentimentales o religiosos van a prevalecer sobre los económicos (GONZÁLEZ VILLARRUEL, 2010).

Los objetos, extraídos del dominio económico de la compraventa existen en de todas las sociedades agrarias tradicionales y los Pedroches no son la excepción. Las familias guardan con veneración los tejidos bordados de los ajuares de sus mayores, la tartera de corcho tallada con motivos geométricos o florales, los sellos de pan en madera de olivo grabados a navaja y que el novio debiera de aportar como parte de su dote, etc.

Las formas, los motivos decorativos empleados, las técnicas utilizadas tienen como resultado unos objetos de gran calidad estética o visual, sin llegar a entorpecer en ningún caso las cualidades funcionales de los instrumentos, que tampoco pierden la sencillez, dada su escasa entidad o la modestia de los materiales empleados.

\section{Conclusiones}

Los artefactos cotidianos de la sociedad agraria de los Pedroches, en los que se reconocen los habitantes de la comarca, son testimonios que ayudan a entender una cultura y una forma de relación sostenible entre el hombre y el medio. Todas las manifestaciones de esta sociedad apuntaban en dicha dirección: el hábitat, las explotaciones agrarias, los oficios tradicionales, etc. $Y$ sus bienes de uso cotidiano y patrimonio mueble lo hacen también en el mismo sentido.

Investigar la cultura material, que ha sido una de las mayores preocupaciones teóricas de la antropología, sigue siendo igualmente valido en el presente para entender, no solo procesos de evolución social, de aculturación o cambio, sino para entender el sentido simbiótico de una cultura material con la naturaleza, de la que el artesano obtiene los materiales y la inspiración o los modelos para su elaboración.

Los museos locales deben de ser conscientes -como apunta Valades (2015) - que son guardianes de un patrimonio excepcional, depositarios de la memoria colectiva, dinamizadores del turismo, pero también armonizadores sociales. De ahí que sea conveniente entender que los objetos expuestos deben de servir para explicar las estructuras, los procesos o el sentido de la sociedad agraria de los Pedroches. Un puntal fundamental de la gestión del patrimonio descansa en el traslado a la ciudadanía del conocimiento de la cultura material propia. La difusión del patrimonio cultural y de las actuaciones que sobre él se desarrollan debe comenzar en la enseñanza reglada y ampliarse a todas las edades, de manera que la ciudanía en conjunto descubra y disfrute dicho patrimonio, al tiempo que toma conciencia de la necesidad de su conservación

El patrimonio mueble de los Pedroches, junto a su patrimonio natural, histórico y cultural convierte a la comarca en uno de los espacios más interesantes de Andalucía, un territorio con identidad propia en el que predomina un sentido unitario, modesto, sencillo, pero a la vez sólido y en sintonía con el territorio y sus recursos. 


\section{BIBLIOGRAFIA}

- AGUDO TORRICO J. (2014) Rituales y festejos en el valle de los Pedroches. Imágenes simbólicas de un territorio de frontera. $\mathrm{PH}$ Boletín del Instituto Andaluz del Patrimonio Histórico, n. ${ }^{\circ} 22$, n. ${ }^{\circ} 86$, pp. 66-75

- Appadural, A. (1991) la vida social de las cosas. Perspectiva cultural de las mercancías. México: Grijalbo/ Conaculta, 1991

- CABANAS, R. (1967) Los Pedroches. Estudios geográficos, vol. 28, n. $^{\circ} 106,1967$, pp. $23-88$

- FERNÁNDEZ CACHO, S.; FERNÁNDEZ SALINAS, V.; HERNÁNDEZ LEÓN E. et ál. (2010) Paisajes y patrimonio cultural en Andalucía. Sevilla: Junta de Andalucía, Consejería de Cultura, Instituto Andaluz del Patrimonio Histórico, vol. 2 (PH Cuadernos, n. ${ }^{\circ}$ 27)

- GONZÁlez VILLARRUEL A. (2010) La vida social de los objetos etnográficos y su desalmada mercantilización. Alteridades, jul./dic. 2010, vol. 20, n. ${ }^{\circ} 40,2010$, pp. 65-76

- LUQUe REVUelto, R. (2012a) Poblamiento y hábitat rural en la Sierra de Córdoba. Córdoba: Universidad de Córdoba, Servicio de Publicaciones, 2012

- LUQUE REVUELTO, R. (2012b) Conocer para valorar y proteger: la vivienda popular mariánica. e-rph, Revista electrónica de Patrimonio Histórico, diciembre, n. 11,2012 , pp. 134-152

- MALINOWSKI, B. (1931) La Cultura. En KAHNJ. S. (comp.) El concepto de cultura. Textos fundamentales. Barcelona: Anagrama, Biblioteca Anagrama de Antropología, 1975, pp. 85-127

- MORENO VALERO, M. (2001) La vida tradicional en los Pedroches. Córdoba: Tipografía Católica, 2001

- TORRES ESQUIVIAS, J. A. (coord.) (1994) Córdoba Natural. Córdoba: Caja Provincial de Ahorros, 1994

- VALADÉS SIERRA, J. M. (2015) Patrimonio e identidad. Representaciones de la cultura regional en los museos etnográficos de Extremadura. Revista Andaluza de Antropología, n. ${ }^{0}$ 9, septiembre, 2015 pp. 158-186

- VALLE BUENESTADO, B. (1986) Geografía agraria de Los Pedroches. Córdoba: Diputación Provincial, 1986

- VALLE BUENESTADO, B. (2016) La Sierra Morena cordobesa: naturaleza, génesis del paisaje y patrimonio ambiental. Revista ph, n. ${ }^{\circ}$ 90, octubre 2016, pp. 30-47 